\title{
Uma nota didáctica breve no uso esclarecido de procedimentos estatísticos em análise de dados repetidos no tempo. Um estudo guiado para investigadores das Ciências do Desporto
}

\author{
José A. R. Maia ${ }^{1}$ \\ Rui M. Garganta ${ }^{1}$ \\ André Seabra ${ }^{1}$ \\ Vitor P. Lopes ${ }^{2}$ \\ António Prista ${ }^{3}$ \\ Duarte Freitas $^{4}$
}

https://doi.org/10.5628/rpcd.04.03.115

\section{RESUMO}

Este texto pretende ser um auxiliar didáctico no uso esclarecido de procedimentos estatísticos relativos à análise longitudinal de dados. Servir-nos-emos de um exemplo ilustrativo de complexidade crescente para introduzir a estrutura de um delineamento de grupo único e da essência do ensaio de hipóteses estatísticas. De seguida apresentamos os principais resultados do uso de teste t e da análise de variância de medidas repetidas. Os resultados são interpretados de modo formal e substantivo, introduzindo um pensamento alternativo à estrutura binária do resultado do ensaio de hipóteses. O recurso a procedimentos gráficos é fortemente explorado. Finalmente, recorre-mos à modelação hierárquica para salientar a sua riqueza e fle-xibilidade interpretativa no estudo de dados longitudinais.

Palavras-chave: dados longitudinais, teste $t$, análise de variância, exploração gráfica, modelação hierárquica.
${ }^{1}$ Faculdade de Ciências do Desporto e de Educação Física Universidade do Porto, Portugal

${ }^{2}$ Instituto Politécnico de Bragança, Portugal

${ }^{3}$ Faculdade de Ciências da Educação Física e Desporto

Universidade Pedagógica, Moçambique

${ }^{4}$ Secção Autónoma de Educação Física e Desporto

Universidade da Madeira, Portugal

\section{ABSTRACT}

A didactical note on the use of statistical procedures for longitudinal data. A guide for researchers in Sport Sciences

This report aims at being a didactical tool to instruct in the use of statistical procedures related to the analysis of longitudinal data sets. We shall use an example of growing complexity, so that we may introduce the basic ideas of a single group design and the essence of hypothesis testing. The main results of the t test and analysis of variance shall be analyzed. These results are formally and substantively interpreted, and an alternative way of thinking is introduced, as a contrast to the binary results of the hypothesis testing. We shall focus on graphic displays of data. Finally, hierarchical modeling is introduced, mainly its richness and flexibility in terms of interpretation of the data structure at hand.

Key Words: longitudinal data, $t$ test, analysis of variance, graphic displays, hierarchical modeling. 


\section{INTRODUÇÃO}

O propósito essencial desta nota breve não é o de substituir capítulos de um qualquer manual de Estatística, tão pouco instruir no uso exclusivo dos procedimentos do t teste e da análise de variância (ANOVA) ${ }^{1}$. Pretende, isso sim, explorar diferentes alternativas de interrogar um conjunto de dados repetidos no tempo e, deste modo, ser um auxiliar didáctico para um pesquisador iniciante que nem sempre é capaz de se libertar do estereótipo de só se concentrar na magnitude do valor da prova (p), que nem sempre sabe o que significa, mas que espera que seja sempre inferior ao mágico número de $5 \%$. Isto, apesar de na maior parte das vezes não ter reflectido seriamente porque é que tal valor é fixado, "desde longa data", em $5 \%$.

Está pois lançado o propósito desta nota breve. A sua estratégia é bem simples, e percorrerá as seguintes etapas:

Apresentaremos, em primeiro lugar, aspectos essenciais de um delineamento de grupo único com observações repetidas no tempo. Por questões de natureza gráfica, e para não abordar procedimentos mais complexo ${ }^{2}$, limitaremos o número de observações temporais a três.

De seguida discutiremos, do ponto de vista formal e substantivo, o problema do ensaio de hipóteses e o nível do erro que se está disposto a "correr" para rejeitar uma hipótese nula verdadeira.

Os dados para os dois pontos do tempo serão descritos e situados num contexto bem conhecido - resultados numéricos da aplicação de um programa de treino para melhorar a força explosiva dos músculos extensores do joelho.

Em quarto lugar apresentaremos os resultados da aplicação do t teste, onde abordaremos duas interpretações alternativas e bem mais interessantes - a do intervalo de confiança para a média das diferenças e a magnitude do efeito.

Passaremos à exploração gráfica dos resultados centrando a nossa atenção no comportamento ordenado das diferenças e seu significado.

Um novo aspecto do comportamento dos dados nos dois pontos do tempo será explorado a partir da noção de estabilidade das mudanças intraindividuais nas diferenças interindividuais. Será utilizado, aqui, o coeficiente de correlação intraclasse.
Apresentaremos de seguida a vantagem em ter mais do que dois pontos no tempo. O modelo estatístico utilizado será a ANOVA de medidas repetidas. Serão lançadas e discutidas várias possibilidades para ensaio de hipóteses. Discutiremos o problema nuclear da simetria composta ou esfericidade e o recurso alternativo a uma análise univariada ou multivariada.

Abordaremos, tal como no ponto anterior, interpretações alternativas ao teste formal de hipóteses e que são os intervalos de confiança e o eta quadrado $\left(\eta^{2}\right)$. O comportamento dos resultados será explorado graficamente a partir dos diagramas de extremos e quartis (Box plot) e do high-low-close dos dados ordenados. A sua importância e interpretação serão salientadas.

Veremos o interesse em pesquisar aspectos da tendência dos resultados e uma opção bem interessante para o teste de post-hoc ou testes a posteriori.

Trataremos, também, do problema da estabilidade ou tracking das mudanças intraindividuais no seio do grupo de observações, recorrendo ao coeficiente de correlação intraclasse.

Finalmente apresentaremos, ainda que de modo muito breve, diferentes formulações ou modelos que impõem comportamentos distintos aos dados. Para tal recorreremos à modelação hierárquica ou multinível (MHMN), um modelo estatístico altamente versátil e flexível, e bem mais interessante do que a ANOVA.

Os procedimentos gráficos e de análise quantitativa estão implementados nos softwares que utilizaremos, e que são o SPSS 12 e o SYSTAT 10. Porções relevantes dos outputs serão "coladas" no texto para facilitar a sua apresentação e interpretação.

\section{DELINEAMENTO DE GRUPO ÚNICO ASPECTOS ESSENCIAIS.}

O plano conceptual e operativo de uma qualquer pesquisa reclama do investigador, para além do enquadramento teórico das inquietações que emergem dos problemas a investigar, uma atenção redobrada à validade das variáveis utilizadas e fiabilidade da informação, i.e., ao controlo apertado que faz de todo o processo de avaliação e medição. A validade de generalização dos seus resultados depende, sempre, do modo como reflectiu e solucionou as questões centrais da validade interna e externa da sua pesquisa (3). 
O delineamento de grupo único pode assumir várias formas - desde a estrutura mais simples da pesquisa quasi-experimental de pré-pós, até ao estudo mais sofisticado de cross-lagged panel $(5,8,21)$.

O delineamento de grupo único, que procura marcar numa estrutura longitudinal aspectos da história natural de um evento, exige um controlo apertado de todo o processo de medição, por forma a garantir uma elevada qualidade da informação. Este controlo implica a execução de estudos-piloto prévios que informem sobre a precisão de todo o protocolado de avaliação, bem como de uma estrutura designada de reliability in field, única forma de controlar, para efeitos de aprendizagem nas medições, e estimar a magnitude da variância erro implícita em todos os momentos de medição. Estes aspectos remetem-nos, necessariamente, para a frequência de amostragem das medições. Quando lidamos com o lato universo das aptidões físico-motoras, registos semestrais ou anuais são mais do que suficientes para evidenciar verdadeira mudança intraindividual. Contudo, por questões de natureza operativa, pode acontecer que por motivos de monitorização do treino das aptidões haja a necessidade de impor uma outra estrutura na temporalidade das medições, que pode ser uma frequência mensal (20). Aqui enfrentamos, necessariamente, aspectos de variabilidade intraindividual que podem não representar uma verdadeira mudança $e$ uma quantidade associada à verdadeira mudança intraindividual. Há pois que delinear a pesquisa no sentido de recorrer a procedimentos estatísticos suficientemente flexíveis para separar aquilo que é variabilidade intraindividual e aquilo que é mudança intraindividual $(11,15,16,17)$.

\section{O PROBLEMA DO ENSAIO DE HIPÓTESES}

Um dos problemas centrais de toda a investigação de natureza empírica prende-se com o entendimento claro da estrutura conceptual e operativa do ensaio de hipóteses, tal como é entendida no quadro formal da estatística inferencial.

Convém que fique claro, desde já, que uma coisa é o conteúdo semântico da estrutura de uma qualquer hipótese substantiva avançada por um investigador e outra coisa é a sua transposição para o domínio da formulação "simples" em termos estatísticos. É importante que se diga, e de modo inequívoco, que a(s) hipótese(s) avançada(s) pelo investigador raramente é (são) colocada(s) à prova em termos estatísticos. Dito por outras palavras, a hipótese do investigador nunca é formalmente testada. Aquilo que se ensaia é, tão-somente, uma outra hipótese contrária à do investigador, e que este pretende rejeitar, que se designa por hipótese nula. O "caricato" da situação é o seguinte: o investigador assume que a hipótese nula é verdadeira (!), e no entanto pretende rejeitá-la em favor de uma alternativa (a sua hipótese) que nunca testa formalmente, e que portanto aceita se se verificar que os dados fornecem evidência substancial contra a hipótese nula.

No ensaio de hipóteses lida-se com dois conceitos intimamente associados e relativamente aos quais nem sempre se entende a sua diferença e significado. São eles o nível de significância $(\alpha)$ e o valor da prova (p). Para ilustrar a confusão que se estabelece entre a estrutura operativa do ensaio de hipóteses, o $\alpha$ e o p, vamos servir-nos de um exemplo muito bem relatado (5), e que é o seguinte:

Suponha que um dado programa de treino é capaz de alterar o desempenho numa dada tarefa. O nível de significância foi previamente fixado em $5 \%$. Depois de comparar as médias dos grupos experimentais e de controlo (digamos com 10 sujeitos cada um), os resultados obtidos com o teste t independente foram os seguintes: $\mathrm{t}=2.7$; graus de liberdade $=18 ; p=0.001$. Marque agora com verdadeiro ou falso as seguintes possibilidades de conclusão: $1^{\text {a }} \mathrm{A}$ hipótese nula, que estabelecia que não havia diferenças entre populações, é rejeitada completamente;

$2^{\text {a }}$ Encontrou-se a probabilidade da hipótese nula ser verdadeira;

$3^{\text {a }}$ Provou-se, de modo absoluto, a hipótese experimental; $4^{\text {a }}$ Pode deduzir-se a probabilidade da hipótese experimental ser verdadeira;

$5^{\text {a }}$ Sabe-se, se se rejeitar a hipótese nula, que existe a probabilidade em cometer uma decisão errada; $6^{\text {a }}$ Tem-se uma experiência fiável no sentido em que, se fosse hipoteticamente repetida um grande número de vezes, se obteria um resultado significativo em $99 \%$ das ocasiões.

De facto, as seis possibilidades de resposta estão todas erradas. Se quisermos interpretar o resultado 
da experiência com base no valor da prova, a sua correcta interpretação seria a seguinte: há uma probabilidade de 1 em 1000 em obter os dados observados (ou um conjunto de dados que representem um desvio mais extremo da hipótese nula) se a hipótese nula for verdadeira.

Claramente que aquilo que o autor pretende evidenciar (fazendo eco das posições de um número cada vez maior de estatísticos e metodólogos) é, tãosomente, a informação extremamente limitada do valor da prova $(\mathrm{p})$ face à natureza binária da decisão associada ao teste de hipóteses. A sua sugestão, muito mais esclarecedora em termos interpretativos, é recorrer à informação proveniente dos intervalos de confiança, da magnitude do efeito, ou da noção de variância explicada. É este percurso que iremos apresentar com base num exemplo bem simples.

\section{OS DADOS DO ESTUDO}

Os dados desta ilustração provêm de um estudo realizado num conjunto de voleibolistas seniores masculinos. Tratou-se de uma pesquisa que pretendia mapear a "história natural" da resposta ao treino dos atletas que foram submetidos a um programa específico de pliometria ${ }^{3}$, no sentido de melhorar substancialmente o seu desempenho explosivo no salto vertical.

A avaliação da impulsão vertical foi realizada na plataforma de Bosco, e os resultados obtidos referem-se ao salto com contra-movimento. Foi realizado um reteste com uma semana de intervalo numa subamostra de 10 atletas para estimar a fiabilidade do seu desempenho, e o valor obtido do coeficiente de correlação intraclasse foi de 0.87 .

Os resultados dos 20 atletas são pois os seguintes (obtidos em 3 pontos do tempo espaçados, cada um, de 1 mês).
Quadro 1: Valores de impulsão vertical (salto com contra-movimento) dos 20 atletas nos 3 pontos do tempo (valores em $\mathrm{cm}$ ).

\begin{tabular}{c|c|c|c} 
Atletas & $\begin{array}{c}\mathbf{t} 1 \\
\text { (momento 1) }\end{array}$ & $\begin{array}{c}\mathbf{t} 2 \\
\text { [momento 2) }\end{array}$ & $\begin{array}{c}\mathbf{t} 3 \\
\text { (momento 3) }\end{array}$ \\
\hline 1 & 44,0 & 48,5 & 51,5 \\
2 & 37,5 & 46,4 & 49,1 \\
3 & 41,9 & $43, ?$ & 47,4 \\
4 & 45,9 & 49,7 & 53,0 \\
5 & 46,5 & 48,2 & 50,3 \\
6 & 40,7 & 43,6 & 46,5 \\
7 & 40,9 & 43,2 & 46,3 \\
8 & 40,1 & 42,6 & 47,4 \\
9 & 40,3 & 44,5 & 46,9 \\
10 & 40,5 & 43,7 & 47,5 \\
11 & 42,7 & 45,8 & 49,2 \\
12 & 41,3 & 44,3 & 44,3 \\
13 & 42,6 & 45,2 & 47,4 \\
14 & 40,7 & 41,5 & 41,9 \\
15 & 40,7 & 41,2 & 43,1 \\
16 & 41,0 & 43,6 & 44,1 \\
17 & 40,6 & 44,0 & 44,6 \\
18 & 41,4 & 44,1 & 44,9 \\
19 & 41,8 & 41,1 & 41,2 \\
20 & 40,2 & $42, ?$ & 45,6 \\
& & &
\end{tabular}

Teste $\mathrm{t}$

Se partirmos do princípio, e é sempre este o ponto de partida desta pesquisa, que o programa foi bem delineado, é de esperar a sua eficácia que se traduzirá, naturalmente, nos incrementos dos valores de força explosiva dos atletas já no $2^{\circ}$ momento de avaliação (i.e., em t2). É pois esta a hipótese que o investigador gostaria de testar, mas que não consegue realizar de acordo com o formalismo estatístico dos ensaios de hipóteses.

\section{Medidas descritivas e teste formal}

No Quadro 2 temos os resultados das medidas descritivas mais importantes. De t 1 para $t 2$ verificou-se um incremento no valor das médias, de $41.57 \mathrm{~cm}$ passou para $44.38 \mathrm{~cm}$. Regista-se, também, um ligeiro aumento na variação interindividual da performance no salto vertical no segundo momento de avaliação (de 2.04 para $2.36 \mathrm{~cm}$ ). 
Quadro 2: Medidas descritivas do salto vertical de 1 (MOM1) para t2 (MOM2), output obtido no SPSS 12.

Paired Samples Statistics

\begin{tabular}{|ll|l|r|r|c|}
\hline & & & & Std. Error \\
& & Mean & $N$ & Std. Deviation & Mean \\
\hline Pair & MOM1 & 41,5650 & 20 & 2,03787 &, 45568 \\
1 & MOM2 & 44,3800 & 20 & 2,35721 &, 52709 \\
\hline
\end{tabular}

Os principais resultados do teste t estão no Quadro 3. O valor da média das diferenças é de $2.82 \mathrm{~cm}$ (incremento médio de t1 pata t2). Dado que $t(19)=-$ 6.655, $\mathrm{p}<0.001$, rejeita-se a hipótese nula $\left(\mathrm{H}_{0}: \mu_{\mathrm{d}}=0\right)$. Se a hipótese nula fosse verdadeira, a probabilidade de se verificar uma média de diferenças na impulsão vertical da magnitude de $2.82 \mathrm{~cm}$ por mero acaso seria menor do que 1 vez em 1000. Dado que a probabilidade é extremamente baixa, há que rejeitar a hipótese nula e aceitar a alternativa, que é a do pesquisador e que não é submetida a qualquer teste formal. Esta só é aceite caso se rejeite a que lhe é oposta, a nula.

De um modo estatístico, trata-se aqui de testar a hipótese do programa não ter tido qualquer eficácia, o que é à partida uma insensatez, dado ser contrária àquilo que está nos planos do investigador. Mas é assim mesmo. Não há qualquer engano formal. Uma vez que se aceita a hipótese alternativa, a que sugere que há ganhos significativamente diferentes de zero, estamos a suportar, indirectamente, a eficácia do programa na melhoria da força explosiva dos membros inferiores dos atletas. E nada mais há a extrair do teste formal de hipóteses, i.e., aquilo que o teste formal dá é tão-somente um contributo numa decisão dicotómica e que é efectuada em termos probabilísticos.

Quadro 3: Resultados da aplicação do teste t (output do SPSS 12).

Paired Samples Test

\begin{tabular}{|c|c|c|c|c|c|c|c|c|}
\hline & \multicolumn{5}{|c|}{ Paired Differences } & \multirow[b]{3}{*}{ t } & \multirow{4}{*}{ df 19} & \multirow{4}{*}{ Sia (2-tailed) } \\
\hline & \multirow[b]{2}{*}{ Mean } & \multirow[b]{2}{*}{ Std. Deviation } & \multirow{2}{*}{$\begin{array}{l}\text { Std. Error } \\
\text { Mean }\end{array}$} & \multicolumn{2}{|c|}{$\begin{array}{l}95 \% \text { Confidence } \\
\text { Interval of the } \\
\text { Difference }\end{array}$} & & & \\
\hline & & & & Lower & Unoer & & & \\
\hline Pair 1 MOM1 - MOM2 & $-2,81500$ & 1,89161 &, 42298 & $-3,70030$ & $-1,92970$ & $-6,655$ & & \\
\hline
\end{tabular}

\section{Interpretação alternativa}

Uma interpretação alternativa ao resultado formal do teste de hipóteses, que só informa sobre a rejeição ou não da hipótese nula, é centrar a nossa atenção na elucidação da "qualidade" das mudanças ocorridas. Vejamos, pois, o resultado do intervalo de confiança a 95\% para a média das diferenças, e que é de 1.93 a 3.70. Isto significa que em termos populacionais, e se submetêssemos os atletas seniores de voleibol a um programa pliométrico igual ao do presente estudo, a média dos ganhos situar-se-ia, com uma confiança de $95 \%$, entre 2.0 e $4.0 \mathrm{~cm}$, aproximadamente. A questão que aqui se levanta é justamente saber, se os resultados que se encontram neste intervalo são relevantes em termos de expressão de força explosiva para se submeter atletas a um programa desta natureza. Se pensarmos, também, em termos da magnitude do efeito em termos relativos [( $\left(\right.$ Media $_{\mathrm{t} 2}$-Media ${ }_{\text {t1 }}$ )/Média ${ }_{\mathrm{t} 1}$ ) x100], os ganhos de força explosiva só reflectem a "história natural" desta mudança em cerca de $7 \%$. Uma vez mais poderíamos perguntar se um programa bem delineado e que implicou 4 treinos semanais durante 4 semanas só consegue induzir alterações percentuais numa magnitude de $7 \%$. A representação gráfica relativa aos ganhos individuais expressos em termos percentuais está na figura seguinte. 


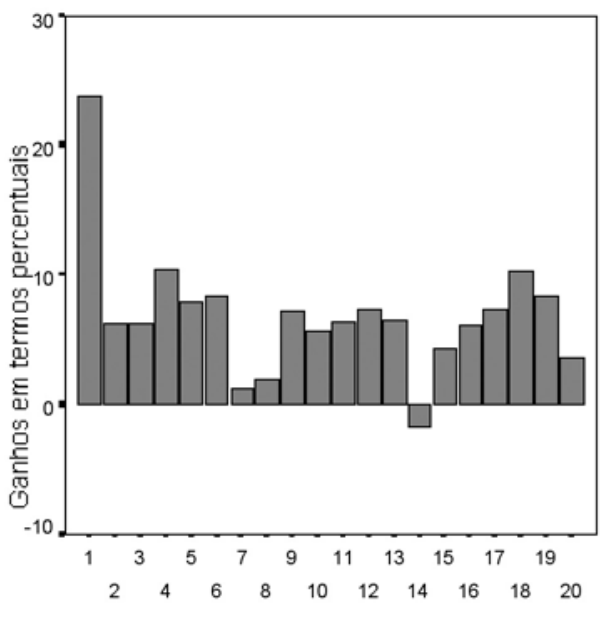

Atletas

Figura 1: Ganhos individuais de t1 para t2 expressos em termos percentuais.

Uma forma gráfica interessante e alternativa da anterior no olhar das alterações que ocorrem de $\mathrm{t} 1$ para t2 é a que representa, de modo ordenado, os resultados numéricos das diferenças de valores de cada atleta (Figura 2).

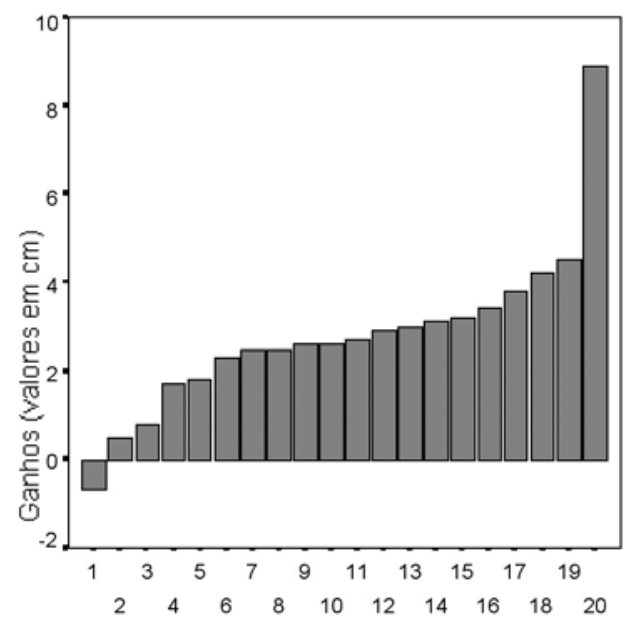

Sujeitos

Figura 2: Representação gráfica dos ganhos em termos absolutos, ordenados pelo valor mais baixo (output obtido no SPSS 12).
Estamos diante de uma representação que salienta alguma heterogeneidade individual na resposta ao treino e que pode ter explicações variadas de natureza neuro-muscular. Há 1 atleta que diminui o seu valor de impulsão vertical, há quem ganhe de 1 a 2 $\mathrm{cm}$, de 3 a $4 \mathrm{~cm}$, ou mais de $8 \mathrm{~cm}$. A questão a explorar é saber a que se deve a circunstância de haver sujeitos com "resistência" à mudança nos seus valores de força explosiva, enquanto que há outros de forte sensibilidade ao treino pliométrico.

\section{Estabilidade}

Os atletas não têm todos o mesmo valor de partida (em t1), dado que o desvio-padrão é de $2.04 \mathrm{~cm}$. É pois provável que a sua resposta ao treino seja distinta (conforme vimos anteriormente). Nesta circunstância, é importante verificar se os ganhos de $t 1$ para $t 2$ evidenciam estabilidade, i.e., se não se identificam cruzamentos nas trajectórias interindividuais (ver Figura 3).

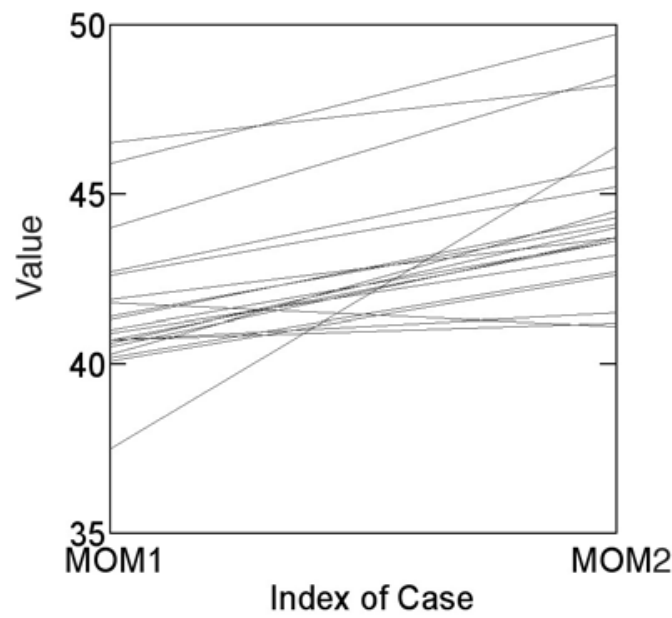

Figura 3: Trajectórias dos atletas de 11 (MOM1) para t2 (MOM2], gráfico obtido no SYSTAT 10.

De facto, há cruzamentos nas trajectórias dos atletas. O coeficiente de correlação intraclasse (obtido no SPSS 12) é de 0.774 (ler na linha average measures), com um intervalo de confiança de 0.429 a 0.911 (ver porção do output no Quadro 4), indiciador 
de alguma instabilidade nos ganhos e que reflecte a ausência de forte manutenção da posição relativa dos sujeitos no seio do grupo.

Quadro 4: Estatísticas relativas ao coeficiente de correlação intraclasse (average measures].

Intraclass Correlation Coefficient

\begin{tabular}{|c|c|c|c|c|c|c|c|}
\hline & \multirow{2}{*}{$\begin{array}{l}\text { Intraclass } \\
\text { Correlation }\end{array}$} & \multicolumn{2}{|c|}{$95 \%$ Confidence Interval } & \multicolumn{4}{|c|}{ F Test with True Value 0} \\
\hline & & Lower Bound & Upper Bound & Value & df1 & $\mathrm{df} 2$ & Siq \\
\hline Single Measures &, $631^{6}$ &, 273 &, 836 & 4,427 & 19,0 & 19 & ,001 \\
\hline Average Measures &, $774^{\mathrm{c}}$ & ,429 & 911 & 4,427 & 19,0 & 19 & 001 \\
\hline
\end{tabular}

Two-wav mixed effects model where people effects are random and measures effects are fixed.

a. Type $C$ intraclass correlation coefficients using a consistency definition-the between-measure variance is excluded from the denominator variance.

b. The estimator is the same, whether the interaction effect is present or not.

c. This estimate is computed assuming the interaction effect is absent, because it is not estimable otherwise.

\section{ANOVA}

Dois pontos no tempo definem, exclusivamente, uma recta. Contudo, não é pacífico, no domínio das variáveis de interesse no território das Ciências do Desporto, que os fenómenos a observar tenham comportamentos que possam ser descritos exclusivamente por rectas. Com mais pontos de registo temporal é possível identificar outros comportamentos nos dados, os quais podem ser de natureza não-linear. Ainda que a maioria dos autores sugira que 4 pontos são o mínimo necessário para se ter uma noção mais adequada do comportamento de uma variável, neste exemplo só consideraremos 3 pontos, tal como foi explicado no início do texto.

Aquilo que aqui se pretende verificar é, uma vez mais, a hipótese substantiva do pesquisador. Dado que o programa foi bem delineado e os atletas responderam com empenho e sem qualquer falta ao treino, é de esperar que a sua resposta, ainda que evidencie alguma variabilidade, seja traduzida em incrementos distintos nas médias nos três pontos do tempo. A haver mudanças na força explosiva dos membros inferiores, a única causa plausível é a que se refere à aplicação do programa. No caso vertente, é formulada, em termos estatísticos, a seguinte hipótese: $\mathrm{H}_{0}: \mu_{1}=\mu_{2}=\mu_{3}$ (contra a alternativa, $\mathrm{H}_{1}: \mu_{\mathrm{i}} \neq \mu_{\mathrm{j}}$, i.e., pelo menos duas médias em dois pontos do tempo são significativamente diferentes). Uma vez mais enfrentamos a situação da ausência de qualquer teste formal à hipótese do investigador que refere, justamente, que o programa foi eficaz, e que portanto há diferenças significativas nos valores médios de força explosiva em pelo menos dois pontos do tempo. Como não há um teste formal àquilo que o investigador pretende evidenciar, há que testar a validade de $\mathrm{H}_{0}$, e esperar que seja rejeitada! E bem mais difícil de entender é a assunção de que é verdadeira!

\section{Medidas descritivas e teste formal}

No Quadro 5 estão descritos os resultados numéricos das estatísticas elementares para os três pontos no tempo. Verifica-se um incremento nas médias, que é mais ou menos equivalente entre pontos adjacentes no tempo. Constata-se, também, que a variabilidade do desempenho aumenta no tempo, já que se verifica um ligeiro incremento nos valores dos desvios-padrão.

Quadro 5: Medidas descritivas da força explosiva nos três pontos do tempo (output do SPSS 12).

\section{Descriptive Statistics}

\begin{tabular}{|l|l|r|r|}
\hline & Mean & Std. Deviation & \multicolumn{1}{|c|}{ N } \\
\hline MOM1 & 41,5650 & 2,03787 & 20 \\
MOM2 & 44,3800 & 2,35721 & 20 \\
MOM3 & 46,6100 & 3,05664 & 20 \\
\hline
\end{tabular}


Independentemente de se assumir que os registos repetidos no tempo são independentes e provêm de uma distribuição normal multivariada, é importante assumir, também (ainda que não seja uma condição necessária), simetria composta para a matriz de covariância das medidas repetidas. Trata-se aqui de assumir que as variâncias dos resultados nos 3 pontos do tempo são iguais e que as covariâncias entre momen- tos são também iguais. Uma face da simetria composta refere-se, exclusivamente, à noção de esfericidade ou circularidade, que trata da noção de que as variâncias nos três pontos do tempo não devem ser significativamente diferentes entre si. O teste formal da ANOVA de medidas repetidas assenta nestes pressupostos. Uma forma de verificar o pressuposto da esfericidade é recorrer ao teste W de Mauchly (ver Quadro 6).

Quadro 6: Resultados do teste W de Mauchly ao pressuposto da esfericidade (output do SPSS 12).

Mauchly's Test of Sphericity

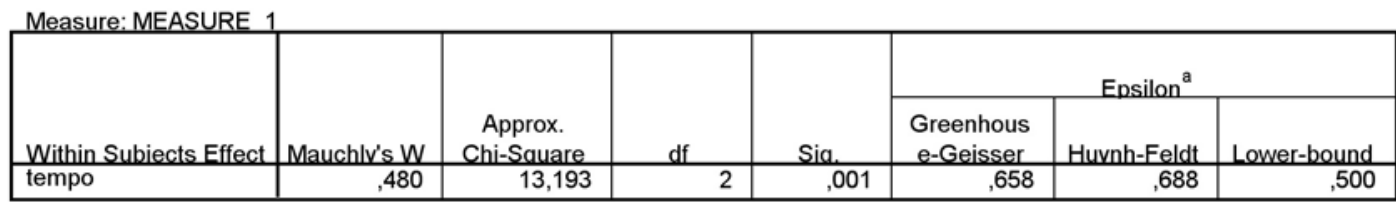

Tests the null hypothesis that the error covariance matrix of the orthonormalized transformed dependent variables is proportional to an identitv matrix.

a. May be used to adjust the degrees of freedom for the averaged tests of significance. Corrected tests are displayed in the Tests of Within-Subjects Effects table. b.

Design: Intercept

Within Subjects Design: tempo

Dado que o valor da prova do teste é de 0.001, é rejeitada a hipótese da esfericidade. A extensão desta violação é reflectida num parâmetro designado de epsilon. Quando se verifica que a matriz de covariância das medidas repetidas não viola o pressuposto de esfericidade, o parâmetro epsilon é igual a 1. O pior resultado da violação é dado por $1 /(\mathrm{k}-1)$, em que $\mathrm{k}$ é igual ao número de medidas repetidas. No nosso caso a estimativa de epsilon é igual a 0.50 e corresponde ao limite inferior do epsilon, conforme é visível no Quadro 6. Greenhouse-Geisser e Huynh-Feldt propõem fórmulas alternativas para o cálculo deste parâmetro e daqui que o seu resultado seja ligeiramente diferente. Como foi violado o pressuposto da esfericidade há que recorrer a uma correcção do teste F da ANOVA com base nas sugestões de Greenhouse-Geisser ou Huynh-Feldt. Estas correcções modificam os valores dos graus de liberdade conforme pode ser consultado no Quadro 7. Ainda que as correcções de Greenhouse-Geisser e Huynh-
Feldt sejam ligeiramente diferentes, uma (Greenhouse-Geisser) mais conservadora do que a outra (Huynh-Feldt), o valor de epsilon, tradutor da magnitude da violação da esfericidade, não é superior a $0.75^{4}$ e o valor da prova é sempre significativo em qualquer das situações, é sugerida a opção pela correcção de Greenhouse-Geisser. A conclusão é pois a rejeição da hipótese nula, dado que $\mathrm{F}(1.316,25.008)=60.898, \mathrm{p}<0.001$. Neste caso aceita-se a hipótese alternativa que é a que o investigador enunciou, mas que não foi verificada directamente pelo teste estatístico formal. 
Quadro 7: Resultados da ANOVA com e sem violação do pressuposto da esfericidade (output do SPSS 12).

Tests of Within-Subjects Effects

\begin{tabular}{|c|c|c|c|c|c|c|c|}
\hline Source & & $\begin{array}{l}\text { Type III Sum } \\
\text { of Squares }\end{array}$ & df & Mean Square & $\mathrm{F}$ & Siq. & $\begin{array}{c}\text { Partial Eta } \\
\text { Squared }\end{array}$ \\
\hline \multirow[t]{4}{*}{ tempo } & Sphericity Assumed & 255,661 & 2 & 127,830 & 60,898 &, 000 &, 762 \\
\hline & Greenhouse-Geisser & 255,661 & 1,316 & 194,240 & 60,898 & ,000 & ,762 \\
\hline & Huynh-Feldt & 255,661 & 1,376 & 185,866 & 60,898 &, 000 & ,762 \\
\hline & Lower-bound & 255,661 & 1,000 & 255,661 & 60,898 &, 000 & ,762 \\
\hline \multirow[t]{4}{*}{ Error(tempo) } & Sphericity Assumed & 79,766 & 38 & 2,099 & & & \\
\hline & Greenhouse-Geisser & 79,766 & 25,008 & 3,190 & & & \\
\hline & Huynh-Feldt & 79,766 & 26,135 & 3,052 & & & \\
\hline & Lower-bound & 79,766 & 19,000 & 4,198 & & & \\
\hline
\end{tabular}

Uma atitude diversa das explicações anteriores é recorrer a um teste multivariado (MANOVA - Análise de Variância Multivariada) que não precisa de assumir esfericidade para se obterem resultados correctos. De facto, e tal como refere por exemplo (5), trata-se de um pressuposto "demasiado forte" para ser verificado numa qualquer condição em que se tenha medidas repetidas no tempo, sobretudo devido à natureza quasisimplex ${ }^{5}$ de uma tal matriz de covariância. O teste multivariado é uma opção mais "sólida". Contudo, tem várias alternativas. Uma das mais utilizadas é o $\Lambda$ de Wilks $=0.139$, que tem uma distribuição amostral muito complexa. É usualmente aproximada para uma distribuição de $\chi^{2}$ de Bartlett ou $\mathrm{F}$ de Rao, cujos resultados são $\mathrm{F}(2,18)=34.981, \mathrm{p}<0.001$. Tanto o teste univariado (ANOVA) como o multivariado (MANOVA) referem-se, exclusivamente, ao teste formal acerca da validade de $\mathrm{H}_{0}$. A ser verdadeira, a probabilidade de ocorrência de um valor tão extremo quanto o obtido na razão F é muito baixa $(\mathrm{p}<0.001)$ e, neste caso, rejeita-se a hipótese nula, tal como tínhamos referido para o caso do teste univariado com o ajustamento de G-G.

Quadro 8: Resultados da MANOVA (output do SPSS 12).

Multivariate Tests

\begin{tabular}{|c|c|c|c|c|c|c|c|}
\hline Effect & & Value & $\mathrm{F}$ & Hypothesis df & Error df & Sia. & $\begin{array}{l}\text { Partial Eta } \\
\text { Squared }\end{array}$ \\
\hline \multirow[t]{4}{*}{ tempo } & Pillai's Trace &, 795 & $34,981^{a}$ & 2,000 & 18,000 &, 000 &, 795 \\
\hline & Wilks' Lambda & 205 & $34,981^{a}$ & 2,000 & 18,000 & ,000 & ,795 \\
\hline & Hotelling's Trace & 3,887 & $34,981^{a}$ & 2,000 & 18,000 & ,000 & ,795 \\
\hline & Roy's Largest Root & 3,887 & $34,981^{a}$ & 2,000 & 18,000 & ,000 & ,795 \\
\hline
\end{tabular}

a. Exact statistic

b.

Design: Intercept

Within Subjects Design: tempo 
O problema a enfrentar agora é o seguinte: se as médias nos três pontos do tempo não são iguais, onde é que se situam as diferenças? Há várias alternativas para testes post-hoc ${ }^{6}$. Contudo, é importante salientar, ainda que se trate de um delineamento de natureza pré-experimental num único grupo, que o teste a posteriori utilizado deverá ser acompanhado de algum pensamento por parte do pesquisador. Dado que ele é a pessoa que conhece bem o proble- ma e aquilo que está "em jogo", deve ter uma atitude bem esclarecida sobre esta matéria. Só assim se compreende a sua opção e justificação. Ora, na ausência de uma qualquer explicação que suporte a escolha de um procedimento de post-hoc ou teste $a$ posteriori, as sugestões que apresentaremos aqui representam pensamentos alternativos. A primeira, contrasta os três momentos entre si ( $\mathrm{t} 1-\mathrm{t} 2$; $\mathrm{t} 1-\mathrm{t} 3$; $\mathrm{t} 2$ t3) e é efectuada com base no teste de Bonferroni ${ }^{7}$ e os resultados estão no Quadro 9.

\section{Pairwise Comparisons}

\begin{tabular}{|c|c|c|c|c|c|c|}
\hline \multirow[b]{2}{*}{ (l) tempo } & \multirow[b]{2}{*}{ (J) tempo } & \multirow{2}{*}{$\begin{array}{c}\text { Mean } \\
\text { Difference } \\
(1-J)\end{array}$} & \multirow[b]{2}{*}{ Std.Error } & \multirow[b]{2}{*}{$\mathrm{Siq}^{\mathrm{a}}$} & \multicolumn{2}{|c|}{$\begin{array}{l}\text { 95\% Confidence Interval for } \\
\text { Difference }\end{array}$} \\
\hline & & & & & Lower Bound & Upper Bound \\
\hline \multirow[t]{2}{*}{1} & 2 & $-2,815^{*}$ & ,423 & , 000 & $-3,925$ & $-1,705$ \\
\hline & 3 & $-5,045^{\star}$ & ,595 & , 000 & $-6,606$ & $-3,484$ \\
\hline \multirow[t]{2}{*}{2} & 1 & $2,815^{\star}$ & ,423 & ,000 & 1,705 & 3,925 \\
\hline & 3 & $-2,230^{*}$ & ,312 &, 000 & $-3,048$ & $-1,412$ \\
\hline \multirow[t]{2}{*}{3} & 1 & $5,045^{\star}$ & ,595 & ,000 & 3,484 & 6,606 \\
\hline & 2 & $2,230^{*}$ & ,312 &, 000 & 1,412 & 3,048 \\
\hline
\end{tabular}

Quadro 9: Resultados do teste de post-hoc com ajustamento de Bonferroni (output do SPSS 12).
É mais do que evidente dos resultados que se verificam diferenças significativas $(\mathrm{p}<0.001)$ entre todos os pontos do tempo. De t1 para t2 verifica-se um incremento médio de $2.815 \mathrm{~cm}$, de $\mathrm{t} 1$ para $\mathrm{t} 3 \mathrm{de}$ $5.045 \mathrm{~cm}$, e de $\mathrm{t} 2$ para $\mathrm{t} 3 \mathrm{de} 2.230 \mathrm{~cm}$.

Uma outra forma de analisar os resultados é realizar somente testes para valores adjacentes no tempo, t1t2 e t2-t3. Os resultados estão no quadro seguinte e mostram-se todos significativos.

Quadro 10: Resultados de testes de post-hoc para valores médios adjacentes no tempo (output do SYSTAT 10)

Univariate F Tests

\begin{tabular}{l|c|c|c|c|c|c}
\multicolumn{2}{l|l}{ Source } & SS & df & MS & $\mathbf{F}$ & $\mathbf{P}$ \\
\hline \multirow{2}{*}{ Error } & 1 & 158.484 & 1 & 158.484 & 44.292 & 0.000 \\
& & 67.985 & 19 & 3.578 & & \\
& 2 & 99.458 & 1 & 99.458 & 51.181 & 0.000 \\
\multicolumn{2}{l}{ Error } & 36.922 & 19 & 1.943 & &
\end{tabular}

\section{Tendência}

Um aspecto importante da análise de medidas repetidas refere-se à possibilidade de identificar a tendência do comportamento temporal da informação. Isto é, de verificar se em função do tempo o comportamento dos valores da força explosiva é de natureza linear ou não linear. Como só temos três pontos no tempo, a análise quantitativa da tendência não pode ultrapassar um polinómio de grau 2. O Quadro 11 refere, justamente, duas possibilidades: linear e quadrática. Ora, a que é estatisticamente significativa é a tendência linear $[\mathrm{F}(1,19)=71.968, \mathrm{p}<0.001]$, conforme veremos na ilustração gráfica dos perfis individuais dos atletas. 
Quadro 11: Teste à tendência dos resultados (output do SPSS 12)

Tests of Within-Subjects Contrasts

\begin{tabular}{|c|c|c|c|c|c|c|c|}
\hline Source & tempo & $\begin{array}{l}\text { Type III Sum } \\
\text { of Squares }\end{array}$ & df & Mean Square & $\mathrm{F}$ & Sia. & $\begin{array}{l}\text { Partial Eta } \\
\text { Sauared }\end{array}$ \\
\hline \multirow[t]{2}{*}{ tempo } & Linear & 254,520 & 1 & 254,520 & 71,968 &, 000 &, 791 \\
\hline & Quadratic & 1,141 & 1 & 1,141 & 1,724 & ,205 & ,083 \\
\hline \multirow[t]{2}{*}{ Error(tempo) } & Linear & 67,195 & 19 & 3,537 & & & \\
\hline & Quadratic & 12,571 & 19 & ,662 & & & \\
\hline
\end{tabular}

\section{Interpretação alternativa}

Já tivemos oportunidade de apresentar alguma argumentação para não nos atermos somente ao valor da prova que reflecte a necessidade exclusiva de uma decisão dicotómica. Bem pelo contrário, aquilo que se exige é largura de visão quando se explora um dado conjunto de dados, por forma a extrair dele toda a informação que contém. Daqui que se recorra, uma vez mais, aos intervalos de confiança e à noção de variabilidade explicada.

No caso dos intervalos de confiança chamamos a atenção do leitor para o Quadro 9. Nas duas últimas colunas temos resultados numéricos relativos a intervalos de confiança a $95 \%$ para as diferenças entre médias. Assim, o intervalo do momento 2 menos o momento $1=1.705$ a 3.925 ; do momento 3 para o momento $2=1.412$ a 3.048 , e do momento 3 para o momento $1=3.484$ a 6.606 . Se centrarmos a nossa atenção exclusivamente neste último, verificamos que em termos populacionais a mudança esperada nos valores da força explosiva se situam, aproximadamente, entre 4 e $7 \mathrm{~cm}$. Uma vez mais a questão a colocar situa-se ao nível da "qualidade" do intervalo destes ganhos, i.e., se reflectem aquilo que é esperado pelo treinador e se reflectem um ganho substantivo em termos de desempenho.

O eta quadrado parcial $\left(\eta^{2}\right)$, é sobretudo uma sobrestimativa do actual valor da magnitude do efeito (SPSS Advanced Models, pag. 327). Refere-se à proporção de variabilidade total atribuível ao factor tempo. No caso do delineamento sobre as alterações da força explosiva, 79.1\% (ver Quadro 11) da variabilidade total observada tem que ser imputada ao factor tempo, que não é mais do que o efeito do programa. Chamamos a atenção que esta interpretação não deve ser confundida com a que foi utilizada no teste $\mathrm{t}$, por se tratar de conceitos e estatísticas diferentes.

\section{Representações gráficas}

O diagrama de extremos e quartis (Box plot) é uma representação gráfica extremamente interessante, dado salientar aspectos nucleares da uma qualquer distribuição de valores numéricos, sobretudo nos seus aspectos de medidas centrais e de dispersão, bem como a eventual presença de resultados que ultrapassam os valores adjacente inferior e superior, e que podem ser candidatos a outliers. Para além de salientar alguma assimetria à direita em $\mathrm{t} 1$ e $\mathrm{t} 2$, observa-se (a) ainda a presença de algumas observações discrepantes nos 3 momentos, (b) o incremento contínuo da variabilidade dos resultados nos 3 pontos, (c) bem como o aumento do valor da mediana.

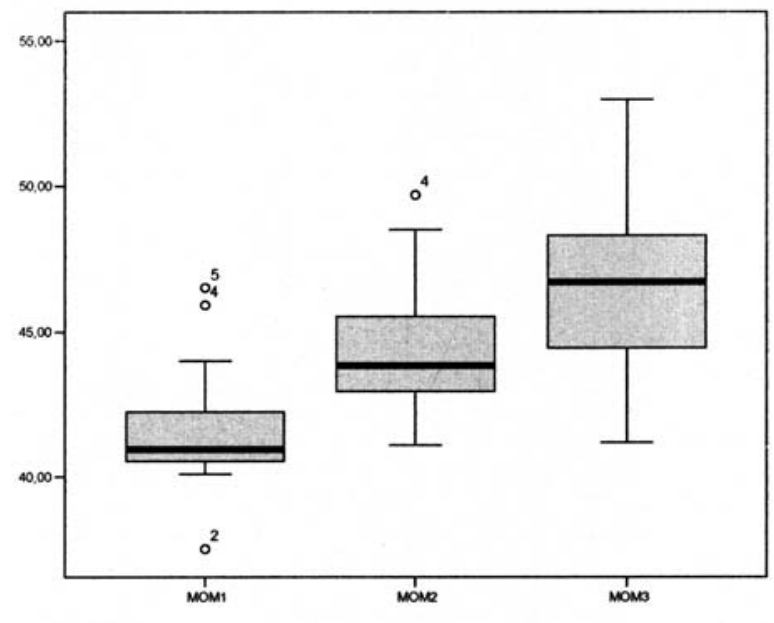

Figura 4: Diagrama de extremos e quartis. 
Este diagrama de high-low-close (high $=\mathrm{t} 3$; close $=\mathrm{t} 2$; low $=\mathrm{t} 1$ ) representado na Figura 5, depois de ordenar os valores por $\mathrm{t} 1$, procura ilustrar vários pontos: (a) a heterogeneidade dos valores de partida; (b) as diferenças nos ganhos que nem sempre parecem estar condicionados aos valores iniciais; (c) a posição relativa dos ganhos em t2 (MOM2) relativamente a t1 (MOM1) e t3 (MOM3). É pois uma representação gráfica bem elucidativa do comportamento díspar na resposta ao treino, por exemplo, dos atletas 1, 8, 18 e 20 .

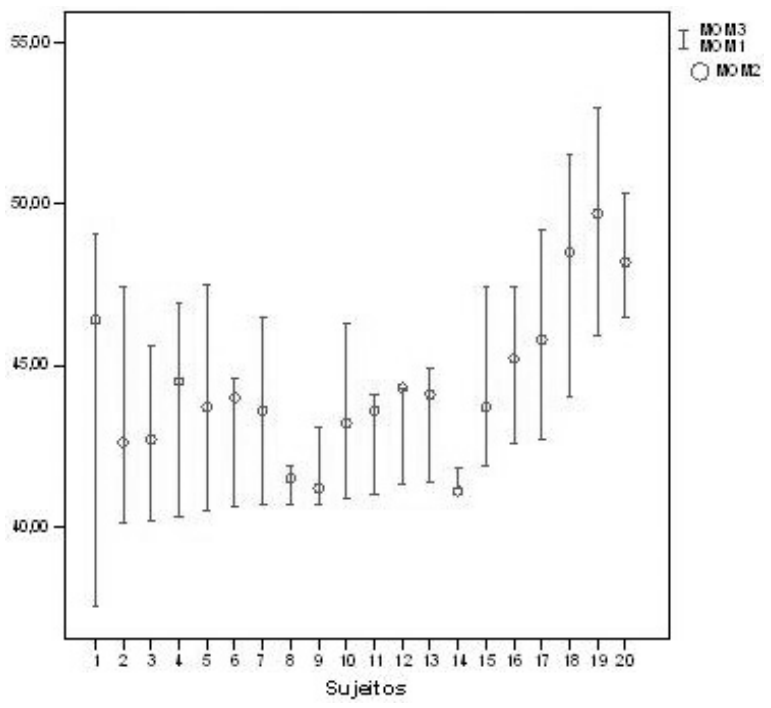

Figura 5: Diagrama de high-low-close.

\section{Estabilidade ou tracking}

A análise da estabilidade ou tracking das mudanças intraindividuais nas diferenças que ocorrem entre sujeitos requer agora um olhar bem mais amplo do que nos resultados do teste $t$.

O primeiro passo consiste, justamente, em observar o traçado das trajectórias dos sujeitos nos 3 pontos do tempo, o que se encontra ilustrado na figura seguinte.

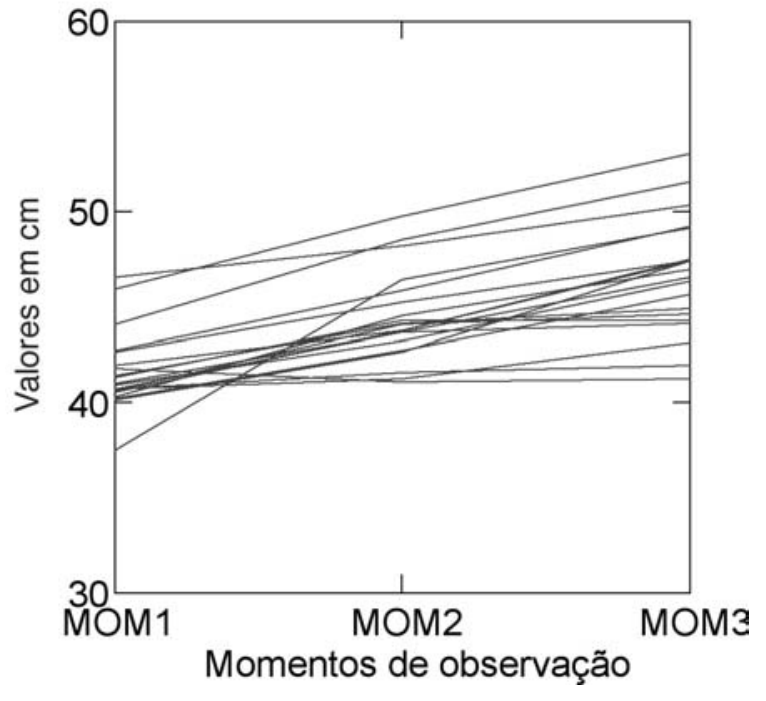

Figura 6: Spargheti plot das trajectórias individuais.

Exige-se, agora, uma análise mais detalhada e ampla dos resultados que se encontram no quadro seguinte: - Na matriz de covariância os valores que mais nos interessam são os que se encontram na diagonal principal (variâncias dos resultados em cada ponto do tempo). Ora, é notório que a variância vai aumentando no tempo, produzindo um efeito de "abertura de leque" nas trajectórias dos sujeitos (confirmado pelos traçados da figura anterior). Isto significa que vai aumentando a heterogeneidade dos valores da impulsão vertical.

- Uma forma expedita de identificar o tracking é verificar o comportamento dos valores de correlação de Pearson entre os três momentos. É evidente que a correlação entre t1 e t3 é moderada $(r=0.516)$. Contudo, acima do valor requerido para um traço ou característica evidenciar tracking $(r \geq 0.50)$. É altamente estável o comportamento da força explosiva de $\mathrm{t} 2$ para $\mathrm{t} 3(\mathrm{r}=0.899)$, ao contrário do que acontece de $\mathrm{t} 1$ para $\mathrm{t} 2(\mathrm{r}=0.638)$. É provável que tal estabilidade esteja associada a efeitos de aprendizagem do próprio processo de avaliação e/ou resposta neuromuscular ao treino.

- A estabilidade global ou tracking é dada pelo valor do coeficiente de correlação intraclasse que é, neste momento, de 0.859 (IC95\%=0.702; 0.940), sugerindo a manutenção moderada a elevada da posição relativa de cada sujeito no seio do grupo. 
Inter-Item Covariance Matrix

\begin{tabular}{|r|r|r|r|}
\hline & \multicolumn{1}{|c|}{ MOM1 } & \multicolumn{1}{c|}{ MOM2 } & \multicolumn{1}{c|}{ MOM3 } \\
\hline MOM1 & 4,153 & 3,066 & 3,211 \\
MOM2 & 3,066 & 5,556 & 6,478 \\
MOM3 & 3,211 & 6,478 & 9,343 \\
\hline
\end{tabular}

The covariance matrix is calculated and used in the analvsis.

Inter-Item Correlation Matrix

\begin{tabular}{|r|r|r|r|}
\hline & \multicolumn{1}{|c|}{ MOM1 } & \multicolumn{1}{|c|}{ MOM2 } & \multicolumn{1}{c|}{ MOM3 } \\
\hline MOM1 & 1,000 &, 638 &, 516 \\
MOM2 &, 638 & 1,000 &, 899 \\
MOM3 &, 516 &, 899 & 1,000 \\
\hline
\end{tabular}

The covariance matrix is calculated and used in the analvsis.

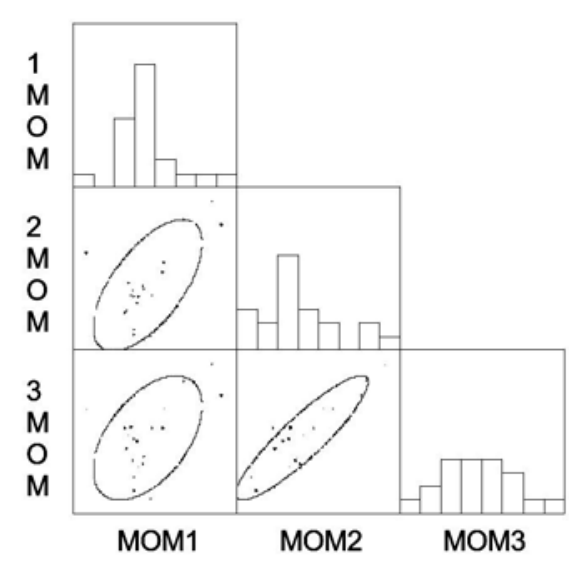

Intraclass Correlatıon Coeftıcıent

\begin{tabular}{|c|c|c|c|c|c|c|c|}
\hline & \multirow{2}{*}{$\begin{array}{l}\text { Intraclass } \\
\text { Correlation }\end{array}$} & \multicolumn{2}{|c|}{$95 \%$ Confidence Interval } & \multicolumn{4}{|c|}{ F Test with True Value 0} \\
\hline & & Lower Bound & Upper Bound & Value & df1 & $\mathrm{df2}$ & Sig \\
\hline ImIgle tvieasules & .009 & .440 &, 039 & 7,010 & 19,0 & 30 &, 000 \\
\hline Average measures & , $85 y^{-}$ &, 102 & y4u & $1,0 / 6$ & $1 y, 0$ & 38 & UUU \\
\hline
\end{tabular}

Two-way mixed effects model where people effects are random and measures effects are fixed.

d. Type $C$ intraclass correlation coefficients using a consistency definition-the between-measure variance is excluded from the denominator variance.

v. The estimator is the same, whether the interaction effect is present or not.

c. This estimate is computed assuming the interaction effect is absent, because it is not estimable otherwise. 


\section{Modelação hierárquica ou multinível (MHMN)}

Não pretendemos terminar este ensaio breve sem sugerir que, com base no pensamento, metodologia e estratégia altamente versáteis e flexíveis da $\mathrm{MHMN}^{8}$ é possível testar, para o mesmo conjunto de dados longitudinais, um corpo variado de hipótesesmodelos hierarquicamente embricados (nested within), por forma a identificar aquele que se afigura mais plausível. Esta versatilidade na formulação de modelos nested within não é possível de realizar com base na ANOVA ou MANOVA. Formularemos quatro modelos ${ }^{9}$ para descrever ${ }^{10}$ o comportamento da força explosiva dos membros inferiores.

$1^{\circ}$ É possível que a variância observada nos valores de partida dos sujeitos (em t1) seja irrelevante, sem qualquer significância estatística. Trata-se de variabilidade biológica sem qualquer significado. Do mesmo modo assumimos que não se verifica qualquer divergência substancial nas trajectórias dos atletas no que respeita aos seus ganhos de força. Neste caso uma única equação de regressão para todo o grupo seria a explicação mais plausível.

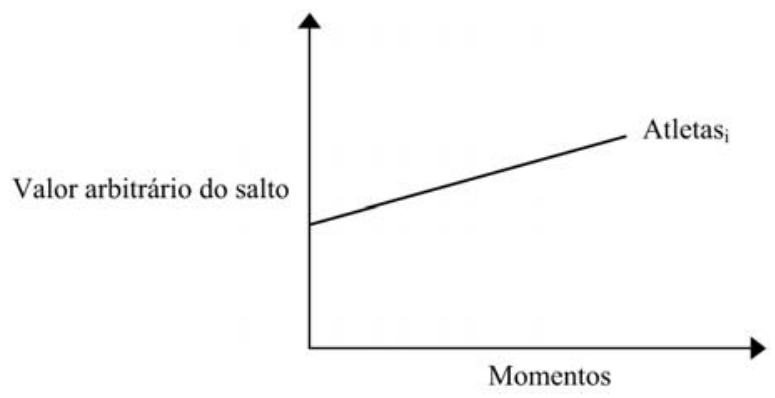

Figura 7: Comportamento dos valores dos atletas em função do tempo para o $1^{\circ}$ modelo.

$2^{\circ}$ Uma outra forma de olhar para o comportamento dos dados seria pensar que ainda que não haja variação significativa no momento inicial (um ponto único serve para descrever os resultados dos atletas em t1), é bem possível que as suas trajectórias sejam diferentes, i.e., que haja variância significativa nos declives das trajectórias dos diferentes atletas, resultado inequívoco das diferenças na sua resposta ao treino e que pode ser de natureza biológica.
Graficamente representaríamos tal possibilidade como na figura 8 .

Valor arbitrário do salto

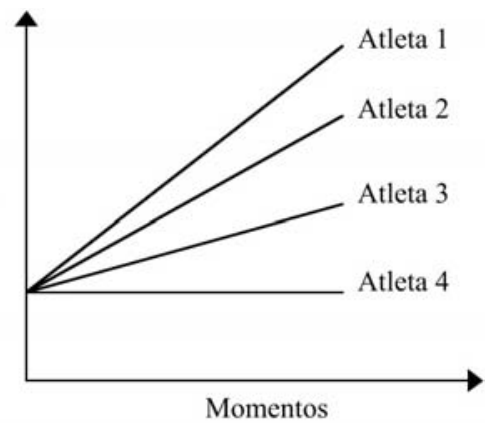

Figura 8: Comportamento dos valores dos atletas em função do tempo para o $2^{\circ}$ modelo.

$3^{\circ}$ É possível pensar, ainda, num formato bem mais flexível para o comportamento das trajectórias interindividuais. Não só os valores de partida dos sujeitos são diferentes entre si, i.e., há variância significativa em t 1 (hipótese contrária às anteriores), como se constata que não existe qualquer diferença nas trajectórias dos sujeitos (a sua resposta ao treino é a mesma, independentemente do seu valor de partida). Trata-se, pois, de especificar rectas paralelas para todos os atletas. Os ganhos de força explosiva no tempo são descritos pelo mesmo declive, aquilo que se designa por estabilidade paralela e que pode representar-se assim (ver Figura 9).

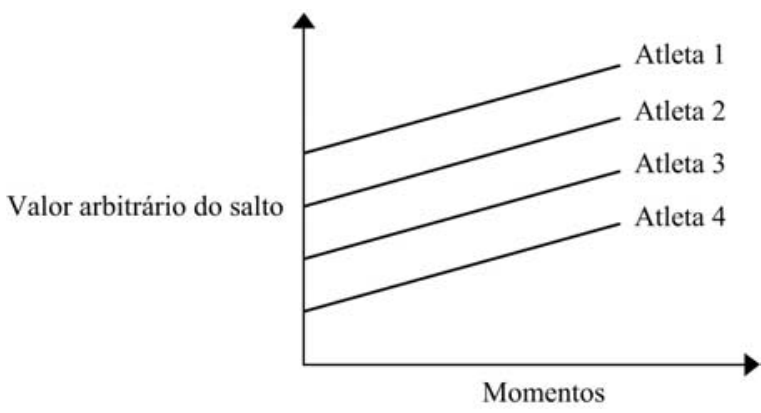

Figura 9: Comportamento dos valores dos atletas em função do tempo para o $3^{\circ}$ modelo. 
$4^{\circ}$ Finalmente, o modelo mais flexível, do qual todos os outros não são mais de que aspectos parcelares, nested within, é o que sugere que não só existe uma variância substancial no momento inicial do estudo (os valores de força explosiva são o resultado da variabilidade biológica e do carácter "residual" da magnitude do destreino ${ }^{11}$ ), como também se verifica uma forte heterogeneidade na resposta ao treino e que é visível no comportamento diferenciado dos valores de força explosiva. Portanto, teríamos trajectórias interindividuais bem diferentes (Figura 10).

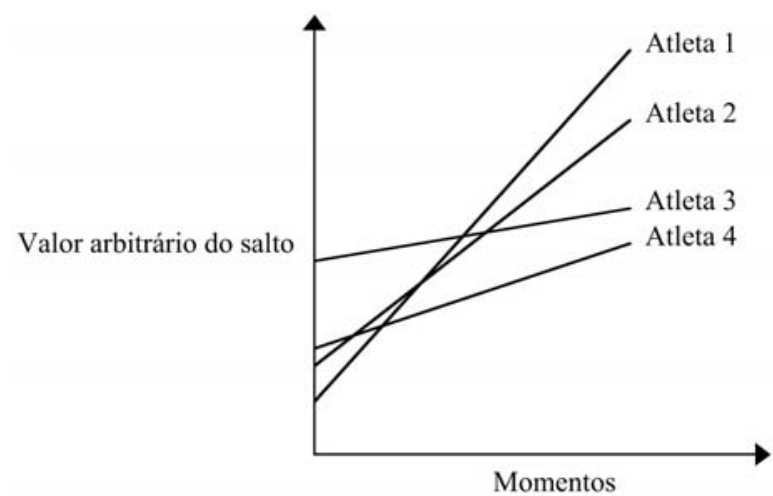

Figura 10: Comportamento dos valores dos atletas em função do tempo para o $4^{\circ}$ modelo.

A forma mais adequada de testar a plausibilidade destes 4 modelos é pensar em termos da sua expansão no que respeita ao número de parâmetros a estimar. O primeiro modelo é o mais simples, e os outros mais complexos. Uma estatística adequada para determinar a qualidade de ajustamento dos dados a uma dada hipótese é a razão do logaritmo da verosimilhança (RV), do inglês log likelihood ratio. Com base no valor desta razão é possível testar a plausibilidade interpretativa de dois modelos, contrastando o mais simples com um outro mais complexo e multiplicando o seu valor por -2 , tal que a estatística $\mathrm{G}=-2 *\left(\mathrm{RV}_{\text {modelo mais restritivo }}-\mathrm{RV}_{\text {modelo mais }}\right.$ expansivo), e esperando que o resultado, que tem uma distribuição de $\chi^{2}$ com número de graus de liberdade igual à diferença dos parâmetros em cada modelo seja significativo (i.e., p<0.05). Os resultados obtidos nos 4 modelos foram os seguintes (Quadro 13).
Quadro 13: Valores da razão do logaritmo de verosimilhança para os 4 modelos testados.

\begin{tabular}{l|c|c} 
Modelos & $\begin{array}{c}\text { RV }[\text { Log da função de } \\
\text { Verosimilhança })\end{array}$ & G \\
\hline Modelo1 & -139.149 & \\
Modelo2 & -129.479 & $19.340\left[\mathrm{M}_{1}-\mathrm{M}_{2}\right]$ \\
Modelo3 & -125.694 & - \\
Modelo4 & -117.274 & $24.41\left(\mathrm{M}_{2}-\mathrm{M}_{4}\right) ; 16.84$ \\
& & $\left(\mathrm{M}_{3}-\mathrm{M}_{4}\right)$
\end{tabular}

Importa salientar que os modelos 2 e 3 não são nested within, mas sim competitivos ou alternativos, dado terem o mesmo número de parâmetros. Qualquer deles seria uma hipótese viável dado terem uma RV praticamente idêntica. Do contraste dos vários modelos e da qualidade do seu ajustamento, fácil se torna verificar que o modelo mais plausível é pois o que postula que não só os valores de partida de força explosiva são diferentes, como também a trajectória dos ganhos evidencia uma variabilidade substancial. Interpretemos, agora, as partes mais importantes do output (Mixed Regression executada no SYSTAT 10). 
Quadro 14: Resultados mais importantes do output da MHMN.

Perform 100 EM iterations

2 random terms

0 fixed terms

Numbers of observations

Level 2 observations $=20$

Level 1 observations $=60$

* Final Results - Maximum Marginal Likelihood (MML) Estimates *

Empirical Bayes estimates:

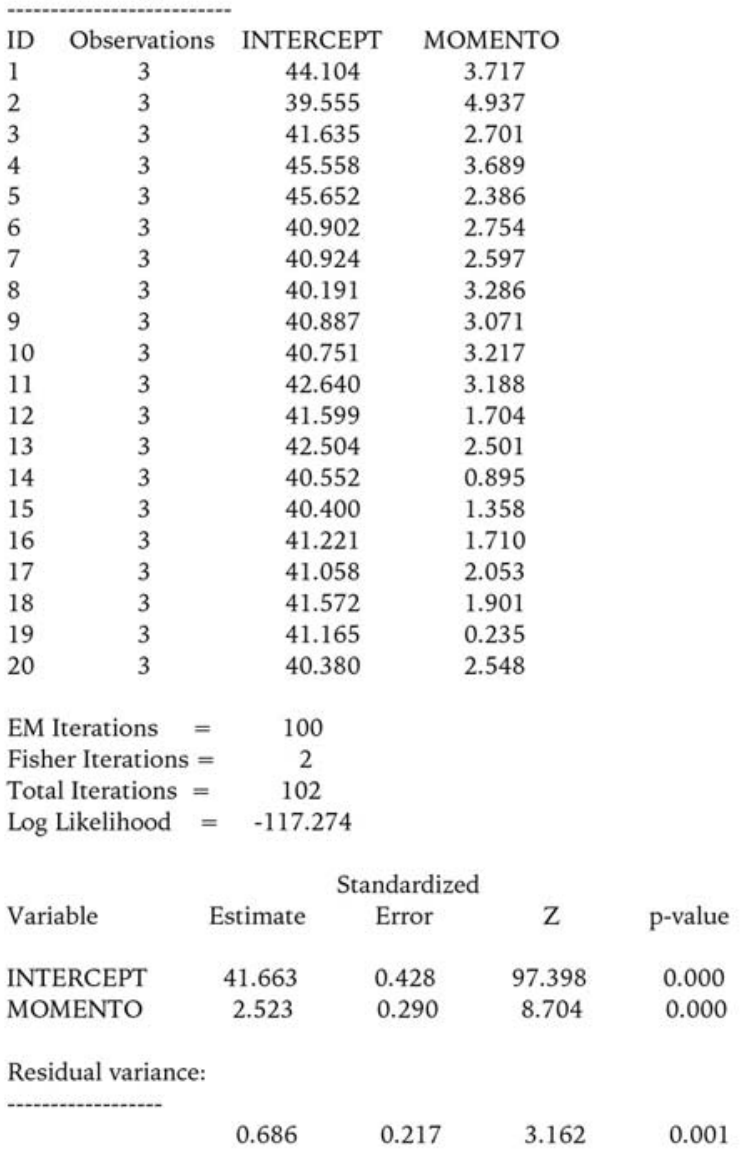

Random-effect variance \& covariance term(s):

$\begin{array}{llcc}\text { Estimate } & & \\ & & 1 & 2 \\ & & \text { INTERCEPT } & \text { MOMENTO } \\ 1 & \text { INTERCEPT } & 3.088 & \\ 2 & \text { MOMENTO } & 0.025 & 1.337\end{array}$

Standardized Error

1 INTERCEPT

2 MOMENTO

$\begin{array}{cc}1 & 2 \\ \text { INTERCEPT } & \text { MOMENTO } \\ 1.171 & \\ 0.569 & 0.542\end{array}$

Z

1 INTERCEPT

$\begin{array}{cc}1 & 2 \\ \text { INTERCEPT } & \text { MOMENTO } \\ 2.637 & \end{array}$

2 MOMENTO

0.044

2.466

p-value

1 INTERCEPT

$\begin{array}{cc}1 & 2 \\ \text { INTERCEPT } & \text { MOMENTO } \\ 0.004 & \\ 0.965 & 0.007\end{array}$

Note: p-values are 2-tailed except for those associated with variances, which are 1-tailed.

Random-effect covariances expressed as correlations

$\begin{array}{lc}1 & 2 \\ \text { TERCEPT } & \text { MOMENTO } \\ 1.000 & \end{array}$
1 INTERCEPT
1.000

Correlation of the MML estimates of the fixed terms 12

1 INTERCEPT

INTERCEPT MOMENTO

2 MOMENTO

1.000

\section{Empirical Bayes Estimate}

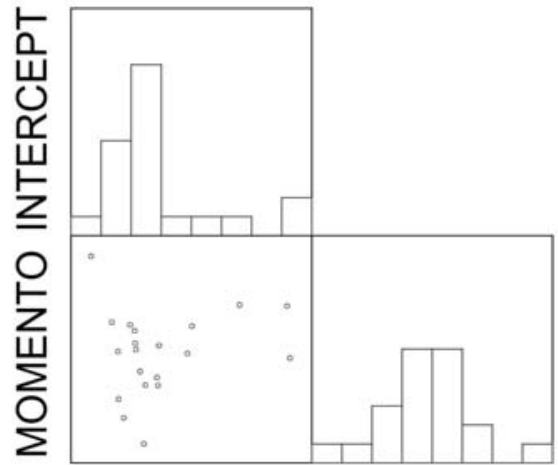

INTERCEPT MOMENTO 
- É evidente a presença de diferenças interindividuais nos valores de partida (ordenada), bem como nas suas trajectórias de modificação da capacidade de salto (declive), tal como é referido nas estimativas individuais apresentadas (Empiral Bayes Estimates). - O valor na ordenada (em t1) é de $41.663 \mathrm{~cm}$ (erropadrão $=0.428$ ), com um resultado da estatística $z=97.398, p<0.001$. O resultado numérico 41.663 é uma estimativa do ponto médio da performance do grupo no início do estudo, dado que $t 1$ foi codificado com o valor 0 . Com base neste resultado seria muito fácil construir um intervalo de confiança com $95 \%$ para aquele valor $(41.663 \pm 1.96 \times 0.428)$.

- O resultado numérico do declive é de 2.523 (erropadrão $=0.290), z=8.704, p<0.001$. Trata-se de um valor que confirma a presença de uma trajectória ascendente nos valores de força explosiva dos atletas. Também aqui seria fácil construir um intervalo de confiança com $95 \%$ para o declive $(2.523 \pm 1.96 \mathrm{x}$ 0.290).

- A verificação da forte heterogeneidade nos valores de partida dos atletas é dada pela estimativa de variância no valor da ordenada e que é de $3.088 \pm 1.171 \mathrm{~cm}(z=2.637, p=0.004)$; o mesmo ocorre para os valores dos declives das trajectórias interindividuais, e que é de $1.337 \pm 0.542(z=2.466$, $\mathrm{p}=0.007$ ).

- Dado que se verifica uma correlação irrelevante $(r=0.012)$ e não significativa $(\mathrm{p}>0.05)$ entre os valores na ordenada e os declives (ver diagrama de dispersão entre intercept e trial), estamos diante da circunstância de não haver qualquer relação entre os valores de partida e os ganhos de força.

- É importante salientar que há variância residual igual a 0.686 (significativa, $\mathrm{p}=0.001$ ) que exige algum esforço suplementar de modelação e que conduziria, necessariamente, para preditores dos sujeitos que originaram as suas diferenças nas trajectórias de desenvolvimento da força explosiva.

- Em resumo, estamos diante de um conjunto de ideias e resultados bem diferentes e porventura mais interessantes e elucidativos do que o simples teste formal à diferença de médias.

Em conclusão, esperamos que este pequeno exercício e viagem guiada a um conjunto simples de dados tenha sido esclarecedor ao ponto de alertar o leitor para uma exploração mais atenta e a uma interpretação mais esclarecida da sua informação.

É importante ter sempre presente a noção de que há que "conversar" com a informação disponível e extrair dela não só sumários relevantes de natureza diversa, como também representações gráficas interessantes e auto-explanatórias do comportamento dos dados.

\section{NOTAS}

1 Chamamos a atenção do leitor para dois textos magistrais no domínio da associação estreita entre argumentação, delineamento de pesquisa e análise de dados $(1,18)$.

2 Uma leitura atenta e cuidada dos textos "A primer in longitudinal data analysis " (23), "Longitudinal data analysis: designs, models and methods" (2), "Modeling longitudinal and multilevel data" (12), "New methods for the analysis of change" (4) será da maior utilidade para o leitor mais exigente e desejoso de mergulhar profundamente neste domínio fascinante.

3 Na sua essência, o programa era constituído por exercícios de pliometria de profundidade.

4 Sobre a matéria da opção pelas correcções de GreenhouseGeisser ou Huyndh-Feldt sugerimos, por exemplo, o estudo dos textos $(6,7,23)$. Uma leitura bem esclarecedora e extremamente didáctica desta matéria pode ser efectuada no texto (26), "Analisis de varianza com medidas repetidas". Uma aplicação ao domínio das Ciências do Desporto pode ser consultada no capítulo 10 do manual "Statistics in Kinesiology" (25).

5 Sobre este assunto consultar (10). Uma aplicação desta noção ao estudo da estabilidade dos valores da actividade física é encontrada em (16).

6 Sobre esta matéria consultar, por exemplo, o manual do SPSS 12 (23).

7 Para evitar a inflação do erro do tipo 1 pelas múltiplas comparações a efectuar, o alfa nominal (global) de $5 \%$ é dividido por três. Nesta situação o alfa de cada comparação individual passa para 0.017 (23) para explorar alternativas no uso dos testes de post-hoc).

8 Este é um brevíssimo apontamento relativo ao uso da MHMN cujas potencialidades na análise de dados longitudinais são extremamente elevadas e muito ricas de pensamento alternativo e mais esclarecedor daquilo que a informação contém. Uma estratégia alternativa à da MHMN é a da Modelação de Estruturas de Covariância (13).

9 Para se identificar com aspectos básicos da MHMN consultar, em língua portuguesa $(16)$, ou os textos nucleares $(9,19)$.

${ }^{10}$ Neste exemplo só se possui informação sobre uma variável de "saída" - a impulsão vertical. É evidente que se estivéssemos na posse de outra informação dos sujeitos e do "ambiente" que variasse, ou não, em função do tempo, poderíamos modelar este conjunto multivariado e encontrar a importância diversa dos factores que explicam as mudanças ocorridas no tempo.

${ }^{11}$ O programa de treino teve lugar logo no início da época desportiva. 


\author{
CORRESPONDÊNCIA \\ José António Ribeiro Maia \\ Laboratório de Cineantropometria \\ e Análise de Dados \\ Faculdade de Ciências do Desporto \\ e de Educação Física \\ Universidade do Porto \\ Rua Dr. Plácido Costa, 91 \\ 4200-450 Porto \\ Portugal \\ jmaia@fcdef.up.pt
}

\section{BILBIOGRAFIA}

1. Abelson RP (1995). Statistics as a principled argument. Mahawah: Lawrence Erlbaum Associates, Publishers.

2. Bijleveld CCJH, van der Kamp LJT, Mooijaart A, van der Kloot WA, van der Leeden R, van der Burg E (1998). Longitudinal data analysis. Designs, models and methods. Thousand Oaks: Sage Publications.

3. Campbell DT, Stanley JC (1963). Experimental and quasiexperimental designs for research. Skokie: Rand McNally.

4. Collins, L.M, Sayer, A.G. (Eds). (2001). New methods for the analysis of change. Washington: American Psychological Association.

5. Cuttance P, Ecob R (1987). Structural equation modeling by example. Applications in educational, sociological, and behavioral research. Cambridge: Cambridge University Press.

6. Everitt BS (1996). Making sense of statistics in psychology. A second-level course. Oxford: Oxford University Press.

7. Field, A (2000). Discovering statistics using SPSS for windows. Advanced techniques for the beginner. Thousand Oaks: Sage Publications.

8. Finkel SE (1995). Causal analysis with panel data. Sage University paper series on Quantitative Applications in the Social Sciences. Thousand Oaks: Sage Publications, 7-105.

9. Hox J (2002). Multilevel analysis. Techniques and applications. Mahwah : Lawrence Erlbaum Associates, Publishers.

10. Joreskog KG (1970). Estimating and testing of simplex models. British Journal of Mathematical and Statistical Psychology 23:121-145.

11. Joreskog KG, Sorbom D (1976). Statistical models and methods for analysis of longitudinal data. In DJ Aigner, AS Goldberger (Eds.) Latent Variables in Socioeconomic Models. Amsterdam: North Holland, 285-325.

12. Little, TD, Schnabel KU, Baumert J (2000). Modeling longitudinal and multilevel data. Practical issues, applied approaches, and specific examples. Mahwah: Lawrence Erlbaum Associates, Publishers.

13. Maia JAR, Beunen G, Lafevre J, Claessens A (1998). Testes empíricos a formulações desenvolvimentalistas: um estudo centrado na modelação da estrutura de covariância. Revista Paulista de Educação Física 12(2):160-180.

14. Maia JAR, Beunen G, Lafevre J, Claessens A, Renson R, Vanreusel B (2003). Modeling stability and change in strength development: a study in adolescent boys. American Journal of Human Biology 4:579-591.

15. Maia JAR, Lopes VP, da Silva RG, Seabra A (2002). A importância do estudo do tracking (estabilidade e previsão) em delineamentos longitudinais: um estudo aplicado à epidemiologia da actividade física e à performance desportivo-motora. Revista Portuguesa de Ciências do Desporto 2(4):41-56.

16. Maia JAR, Lopes VP, da Silva RG, Seabra A, Ferreira JV, Cardoso MV (2003). Modelação hierárquica ou multinível. Uma metodologia estatística e um instrumento útil de pensamento na investigação em Ciências do Desporto. Revista Portuguesa de Ciências do Desporto. 3 (1):92-107.

17. Marsh HW, Grayson D (1994). Longitudinal factor analysis: common, time-specific, item-specific and residualerror components of variance. Structural Equation Modeling 1:116-145.

18. Maxwell SE, Delaney HD (2000). Designing experiments and analyzing data. A model comparison perspective. Mahawah: 
Lawrence Erlbaum Associates, Publishers.

19. Raudenbush SW, Bryk AS (2002). Hierarchical linear models. Applications and data analysis methods. $2^{\text {nd }}$ edition. Thousand Oaks: Sage Publications.

20. Silva PJMM (2003). Estudo da dinâmica da performance em andebolistas júniores. Tese de Mestrado. Faculdade de Ciências do Desporto e de Educação Física, Universidade do Porto. Portugal.

21. Spector PE (1981). Research Designs. Sage University Paper series on Quantitative Applications in the Social Sciences, series $n^{\circ} 35$. Berverly Hills: Sage Publications.

22. SPSS Advanced Models. Chicago: SPSS Inc.

23. Stevens JP (2002). Applied multivariate statistics for the social sciences. $4^{\text {th }}$ edition. Mahawah: Lawrence Erlbaum Associates, Publishers.

24. Taris TW (2000). A primer in longitudinal data analysis. Thousand Oaks. Sage Publications.

25. Vincent WJ (1999) Statistics in Kinesiology. $2^{\text {nd }}$ edition. Champaign: Human Kinetics.

26. Ximénez C, Martin RS (2000). Análisis de varianza com medidas repetidas. Madrid: Editorial la Muralla S.A. 